\title{
ORIGINAL ARTICLE Gene therapy using plasmid DNA-encoded anti-HER2 antibody for cancers that overexpress HER2
}

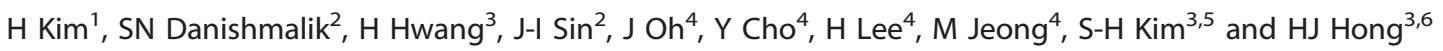

Plasmid DNA-encoded antibodies, or DNA-based monoclonal antibodies (dMAbs), are delivered by intramuscular injection and in vivo electroporation (EP) and are effective in virus neutralization, although they have not been evaluated for tumor gene therapy. Here we investigated whether a dMAb was appropriate for tumor gene therapy. We constructed the expression plasmids coding for the heavy or light chain of a parental murine antibody of Herceptin with the antibody genes codon- and RNA-optimized and fused to the Kozak-lgE leader sequence in pVax1. Transfection of the plasmids into human muscle RD cells resulted in functional expression of the antibody, and this exhibited the same in vitro antiproliferative activity as Herceptin. A single intramuscular injection and in vivo EP of the plasmids ( $100 \mu \mathrm{g}$ per head) resulted in high and sustained antibody expression in the sera of normal mice and in effective inhibition of tumor growth in nude mice bearing HER2-positive human breast carcinoma BT474 xenografts. The antitumor efficacy of the anti-HER2 dMAb was similar to that of four doses of intravenously injected $10 \mathrm{mg} \mathrm{kg}^{-1} \mathrm{Herceptin}$. The results demonstrate that the $\mathrm{dMAb}$ is effective in the treatment of HER2-positive breast cancer, suggesting that this dMAb may be applicable for tumor gene therapy.

Cancer Gene Therapy (2016) 23, 341-347; doi:10.1038/cgt.2016.37; published online 16 September 2016

\section{INTRODUCTION}

Therapeutic antibodies represent the most successful biological drugs. In the past 30 years, $>40$ therapeutic antibodies have been approved for clinical use in various indications, including cancers, autoimmune diseases, infectious disease and neovascular disorders. ${ }^{1}$ Thus therapeutic antibodies represent one of the fastest growing areas of the pharmaceutical industry. The global market for antibody therapeutics in 2014 was $\$ 75$ billion. ${ }^{1}$ The remarkable success was driven by technological evolution from murine monoclonal antibodies (mAbs) to chimeric and humanized antibodies, human mAbs and antibody-drug conjugates. ${ }^{2}$ In oncology, therapeutic antibodies targeting growth factor receptors such as HER2/neu or epidermal growth factor receptor have been proven effective for the treatment of metastatic breast cancer or colorectal and head and neck cancers, respectively. ${ }^{3-6}$

The clinical impact of therapeutic antibodies is remarkable. However, production of the mAbs requires high-cost manufacturing and complicated technologies, especially those associated with large-scale mammalian cell culture and antibody purification. $^{7-9}$ These requirements have limited their application to broader populations, particularly in developing countries. In this regard, the manufacturing for in vivo gene therapy is greatly simplified and the production costs are much lower, which will likely facilitate the application of therapeutic antibodies to a greater population. There are two general approaches to deliver genes into a cell: viral and non-viral. Viral vectors are highly efficient in introducing genes but can create some safety risks, whereas non-viral vectors are much safer than viral vectors but may have inefficient gene delivery. ${ }^{10-13}$
In the past several years, there has been a great advance in the plasmid DNA delivery technology that is utilized for in vivo production of proteins. This included codon optimization for expression in human cells, RNA optimization to improve mRNA stability as well as more efficient translation at the ribosomal level, the addition of specific leader sequences to enhance translation efficiency, the creation of synthetic inserts to further enhance production in vivo and the use of improved adaptive electroporation (EP) delivery protocols to improve in vivo delivery. ${ }^{14-25}$ EP assists in the delivery of plasmid DNA by generating an electrical field at the site of immunization that allows the DNA to pass into the cell more efficiently. ${ }^{26-28}$ Recent studies reported that this advanced plasmid DNA delivery technology was used to generate human Fab or immunoglobulin G1 (IgG1) broadly neutralizing antibody against the HIV or Dengue virus, respectively, in mouse sera after a single intramuscular injection and in vivo EP. ${ }^{29,30}$ To date, however, the synthetic DNA-encoded antibody approach, or DNA-based monoclonal antibody (dMAb) technique, has not been applied to tumor gene therapy.

In the present study, we evaluated a model antibody for tumor gene therapy. We constructed expression plasmids that can express the heavy or light chain of a parental murine mAb (mumAb4D5) $^{31}$ of trastuzumab (Herceptin), which has been clinically used to treat metastatic breast cancers overexpressing HER2, and evaluated in vivo expression and antitumor efficacy after a single intramuscular injection and in vivo EP. The anti-HER2 $\mathrm{dMAb}$ resulted in high and sustained expression of the murine $\mathrm{mAb}$ in mouse sera and effective inhibition of tumor growth in nude mice bearing HER2-positive human breast carcinoma xenografts.

\footnotetext{
${ }^{1}$ Department of Biology, College of National Science, Kangwon National University, Chuncheon, Korea; ${ }^{2}$ BK21 Plus Graduate Program and Department of Microbiology, School of Medicine, Kangwon National University, Chuncheon, Korea; ${ }^{3}$ Department of Systems Immunology, College of Biomedical Science, Kangwon National University, Chuncheon, Korea; ${ }^{4}$ Research Center, GeneOne Life Science, Seoul, Korea; ${ }^{5}$ University-Industry Cooperation Foundation, Kangwon National University, Chuncheon, Korea and ${ }^{6}$ Institute of Bioscience and Biotechnology, Kangwon National University, Chuncheon, Korea. Correspondence: Professor HJ Hong, Department of Systems Immunology, College of Biomedical Science, Kangwon National University, Chuncheon 200701, Korea.
} 


\section{MATERIALS AND METHODS}

Cells and reagents

HEK293T and human muscle RD cells (ATCC CCL-136, Manassas, VA, USA) were cultured in Dulbecco's modified Eagle's medium (Welgene, Gyeonsan-si, Korea) supplemented with $10 \%$ fetal bovine serum (Hyclone, South Logan, UT, USA). Human breast carcinoma BT474 cells were obtained from ATCC (lot number, 59758899) and cultured in Dulbecco's modified Eagle's medium/F12 (Lonza, Walkersville, MD, USA) supplemented with $10 \%$ fetal bovine serum. All cells were cultured in $5 \% \mathrm{CO}_{2}$ in a $37^{\circ}$ $C$ humidified incubator.

Recombinant HER2 (ERBB2-His) was obtained from A\&R Therapeutics (Daejeon, Korea). Anti-mouse $\operatorname{lgG~} \mathrm{F}\left(\mathrm{ab}^{\prime}\right)_{2}$ antibody and horseradish peroxidase(HRP)-conjugated anti-mouse IgG (Fc specific), anti-mouse IgG $(\mathrm{H}+\mathrm{L})$, anti-mouse $\lg \mathrm{G} 1$ and anti-mouse $\lg \mathrm{G} 2 \mathrm{a}$ antibodies were obtained from Pierce Biotechnology (Thermo Fisher Scientific, Rockford, IL, USA).

\section{Construction of 4D5-mlgG antibody expression plasmids}

The light chain variable region (VL) sequence of mumAb4D5 was modified by replacing asparagine at amino acid 65 with serine to remove potential $\mathrm{N}$-glycosylation site. ${ }^{31}$ The modified VL was fused to mouse $C_{K}$ while the heavy chain variable region (VH) of mumAb4D5 was fused to mouse $C_{\gamma} 1$ or Cy2a to express mouse $\operatorname{lgG} 1$ or $\operatorname{lgG} 2 \mathrm{a}$ isotype of mumAb4D5, respectively. The genes encoding the heavy or light chain were flanked with a Kozak-IgE leader sequence and cleavage sites for EcoRl and Notl. The resulting modified genes were codon- and RNA-optimized and synthesized by DNA synthesis service (GeneArt, Thermo Fisher Scientific, Washington, NC, USA), digested with EcoRI and Notl and individually subcloned into the EcoRI-Notl site of pVax1 (Invitrogen Thermo Fisher Scientific, Grand Island, NY, USA) to construct heavy chain (pVax1-4D5-mlgG1-H or pVax1-4D5-mlgG2a-H) and light chain (pVax1-4D5-mlgG-L) expression plasmids, respectively. Purified plasmid DNA was formulated in water for administration into mice.

\section{Expression of 4D5-mlgG in RD and HEK293T cells}

The heavy and light chain expression plasmids were co-transfected into the RD cells or HEK293T cells using the Lipofectamine 2000 transfection reagent (Invitrogen), according to the manufacturer's instruction. Briefly, the cells $\left(1 \times 10^{6}\right)$ were seeded in T75 flask at $24 \mathrm{~h}$ before transfection, and $10 \mu \mathrm{g}$ of the pVax 1 control or mixture of $5 \mu \mathrm{g}$ each of the heavy and light chain expression plasmids was transfected. After transfection, the cells were cultured in serum-free medium for $48 \mathrm{~h}$, and the culture supernatants were subjected to western blotting analysis and quantitative enzymelinked immunosorbent assay (ELISA) to assess the expression levels of the antibody. Supernatants from pVax1-transfected cells were used as a negative control. The culture supernatants of transfected HEK293T cells were subjected to an affinity chromatography on Protein G-Sepharose 4B column (GE Lifesciences, Buckinghamshire, England) for antibody purification, according to the supplier's instruction.

\section{Western blotting analysis}

Supernatants from transfected cells were subjected to $4-12 \%$ Bis-Tris sodium dodecyl sulfate-polyacrylamide gel electrophoresis, and the protein bands in the gel were transferred to polyvinylidene difluoride membranes (Invitrogen). The membranes were incubated with HRPconjugated goat anti-mouse lgG $(\mathrm{H}+\mathrm{L})$ (Pierce), and immunoreactive bands were visualized using a HRP chromogenic substrate (Invitrogen).

\section{Quantitative ELISA}

Microtiter wells were coated with the purified anti-mouse lgG $F\left(a b^{\prime}\right)_{2}$ (100 ng) diluted in $100 \mu \mathrm{l}$ phosphate buffered saline (PBS) at $4{ }^{\circ} \mathrm{C}$ overnight and blocked with skim milk (2\%) in PBS for $1 \mathrm{~h}$ at $37^{\circ} \mathrm{C}$. Subsequently, diluted culture supernatant or normal mouse lgG (Pierce) as standard was added to each well and then incubated at $37^{\circ} \mathrm{C}$ for $1 \mathrm{~h}$. The wells were washed three times with PBS containing $0.05 \%$ Tween 20 (PBST), and then goat anti-mouse lgG (Fc specific)-HRP (1:10 000) was added and incubated at $37^{\circ} \mathrm{C}$ for $1 \mathrm{~h}$. The wells were washed with PBST and developed with OptEIA TMB substrate (BD, San Diego, CA, USA). The absorbance was measured at $450 \mathrm{~nm}$ in a microtiter plate reader (Versa max, Molecular Devices, Sunnyvale, CA, USA).

\section{Indirect ELISA}

Microtiter wells were coated with $100 \mathrm{ng}$ of HER2 (ERBB2-His, A\&R Therapeutics, Daejeon, South Korea) diluted in $100 \mu \mathrm{l} \mathrm{PBS}$ for $4{ }^{\circ} \mathrm{C}$ overnight and blocked with skim milk (2\%) in PBS for $1 \mathrm{~h}$ at $37^{\circ} \mathrm{C}$. After
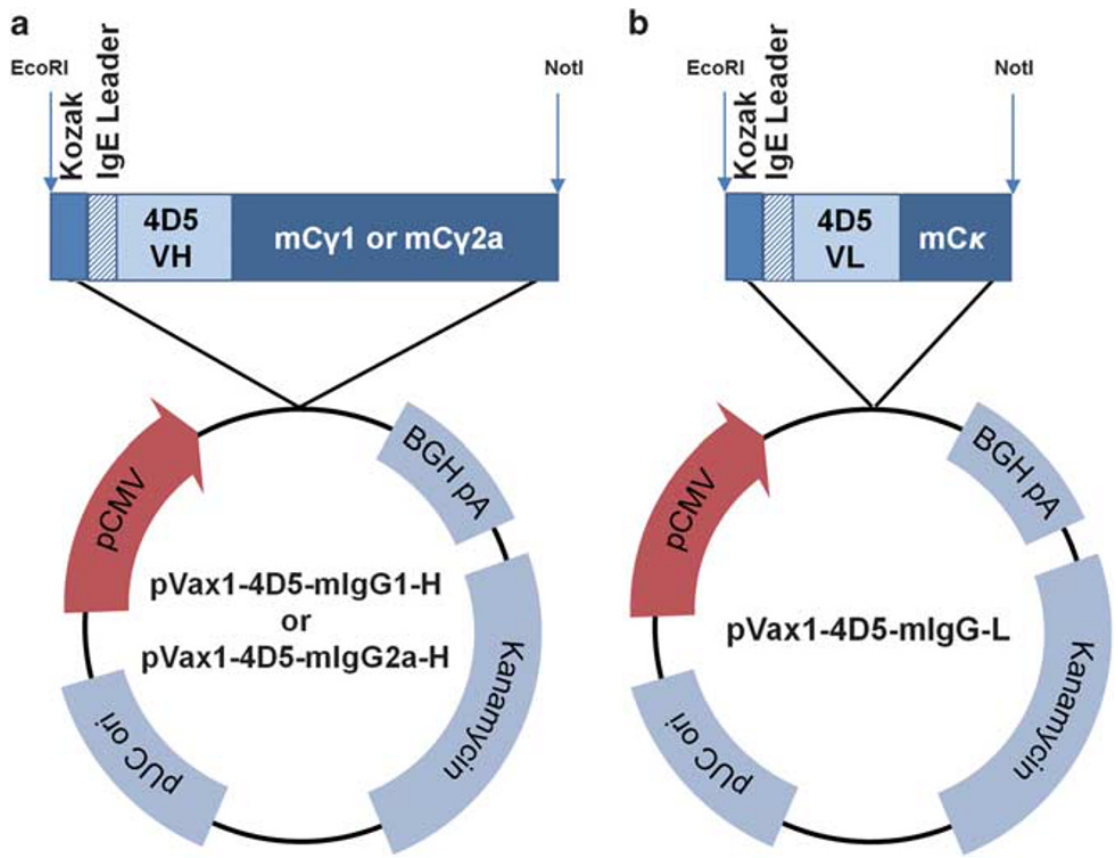

Figure 1. Construction of the heavy (a) and light (b) chain expression plasmids. (a) A sequence was synthesized containing the Kozak-lgE leader sequence, the heavy chain gene encoding the heavy chain variable region (VH) of mumAb4D5 and mC 1 or mC $\gamma 2 a$. This DNA sequence was subcloned into the EcoRI and Notl sites of pVax1 to construct pVax1-4D5-mlgG1-H or pVax1-4D5-mlgG2a-H, respectively. (b) A DNA sequence was synthesized containing the Kozak-IgE leader sequence, the light chain gene encoding the modified light chain variable region (VL) of mumAb4D5 and $\mathrm{mC \kappa}$ and subcloned into pVax1 to construct pVax1-4D5-mlgG1-L. 
incubation, diluted culture supernatant or serum was added to each well and incubated for $1 \mathrm{~h}$ at $37^{\circ} \mathrm{C}$. The wells were washed three times with PBST, and then goat anti-mouse lgG-HRP was added and incubated for $1 \mathrm{~h}$ at $37^{\circ} \mathrm{C}$. The wells were washed and developed as described above. For quantitation of a murine MAb in the mouse sera, purified $4 \mathrm{D} 5-\mathrm{mlg}$ lg1 or 4D5-mlgG2a was used as a standard.

\section{In vivo assessment of 4D5-mlgG expression}

Each $50 \mu \mathrm{g}$ of the heavy and light chain plasmids in a $50 \mu \mathrm{l}$ volume was injected intramuscularly into the female BALB/C mice ( 8 weeks of age), followed by EP using CELLECTRA adaptive constant current EP device (Inovio Pharmaceuticals Inc., Plymouth Meeting, PA, USA). Pulsing parameters for delivery were three pulses of $0.2 \mathrm{Amp}$ constant current, $1 \mathrm{~s}$ apart, $52 \mathrm{~ms}$ in length. Each animal received a single administration of either experimental or control plasmid formulations. The mice were bled and sera were collected at each time point. Mouse sera were diluted to 1:50 and then analyzed by ELISAs.

\section{In vitro tumor cell proliferation assay}

BT474 cells $\left(10^{4}\right.$ cells per well) were seeded in 96-well plates (SPL Life Sciences, Pocheon-si, Korea) and incubated at $37{ }^{\circ} \mathrm{C}$ in $5 \% \mathrm{CO}_{2}$ incubator for $24 \mathrm{~h}$. Different concentrations of antibody were added to each well, and incubation was continued for $72 \mathrm{~h}$. Water-soluble tetrazolium-1 (WST-1) reagent (10 $\mu \mathrm{l}$, Roche Diagnostics $\mathrm{GmbH}$, Mannheim, Germany) was added to each well and the plate was incubated in $5 \% \mathrm{CO}_{2}$ incubator for $2 \mathrm{~h}$. The absorbance was measured at $450 \mathrm{~nm}$ with a reference at $650 \mathrm{~nm}$ in a microplate reader (Versa max, Molecular Devices).

\section{In vivo tumor growth inhibition study}

Female BALB/c nude (nu/nu) mice (4 weeks of age), obtained from Japan SLC, Inc. (Hamamatsu, Japan), were maintained for 2 weeks in a pathogenfree environment, and all animal experiments were performed in accordance with the Biotoxtech Co., Ltd. (Cheongwon-gun, Korea) guidelines established for animal care and use. Estrogen (72 ng) was injected into the left flank of each mouse, and 2 days later, BT-474 cells $\left(5 \times 10^{6}\right.$ cells in $0.1 \mathrm{ml} \mathrm{PBS}$ ) were subcutaneously injected into the right flank of each mouse. To test the antitumor activity of Herceptin, when tumors reached to $108-162 \mathrm{~mm}^{3}$ in size, tumor-bearing mice were randomized into two groups ( $n=8$ per group), and Herceptin $\left(8 \mathrm{mg} \mathrm{kg}^{-1}\right)$ or human Fc (hFc, $2.7 \mathrm{mg} \mathrm{kg}^{-1}$ ) was intravenously injected into each mouse twice a week for 4 weeks. To test the antitumor activity of anti-HER2 dMAb, when tumors reached to $40-60 \mathrm{~mm}^{3}$ in size, $100 \mu \mathrm{g}$ of plasmid DNA (4D5-mlgG2a expression plasmids or pVax1) or water as a control was injected intramuscularly into each animal followed by EP-mediated enhanced delivery by the CELLECTRA adaptive constant current EP device (Inovio Pharmaceuticals Inc.). At day 7, Herceptin $\left(10 \mathrm{mg} \mathrm{kg}^{-1}\right)$ was intravenously injected into each mouse twice a week for 14 days. Body weight and tumor volume were measured twice a week for 22 days. Tumor volume was
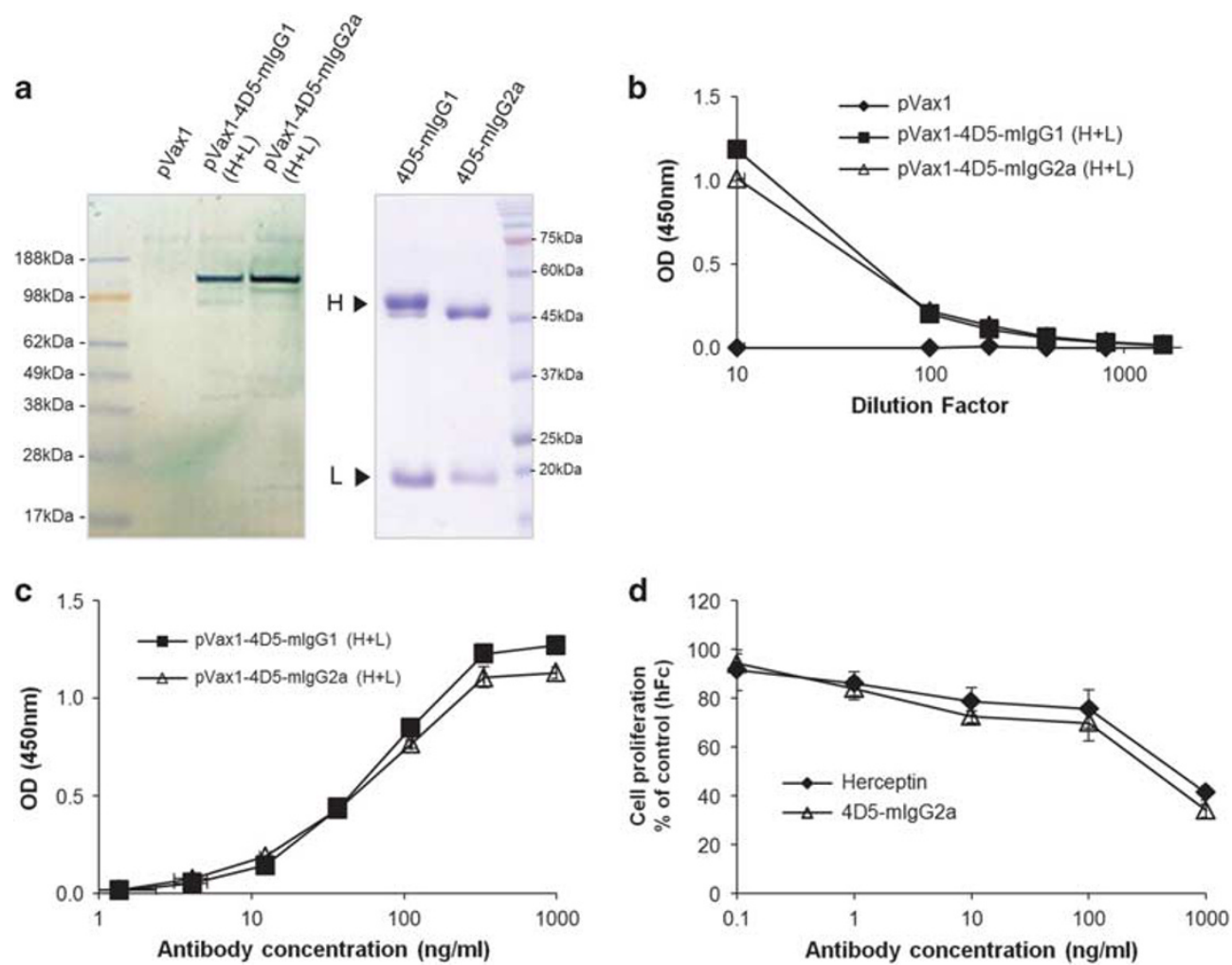

Figure 2. In vitro analyses of the expression and antitumor activity of 4D5-mlgG1 and 4D5-mlgG2a. (a) The human RD cells transfected with pVax 1 as a control or the expression plasmids for mlgG1 or mlgG2a were cultured in serum-free medium, and the culture supernatants $(19.5 \mu \mathrm{l}$ per well) were subjected to western blotting analysis under non-reducing conditions using anti-mouse immunoglobulin $\mathrm{G}$ (lgG)-horseradish peroxidase (HRP) conjugate (left panel). In addition, the 4D5-mlgG1 and 4D5-mlgG2a antibodies purified from the culture supernatant of transfected HEK293T cells were analyzed by $10 \%$ sodium dodecyl sulfate-polyacrylamide gel electrophoresis under reducing conditions (right panel). (b) The amount of the expressed 4D5-mlgG1 or 4D5-mlgG2a in the culture supernatants of the transfected RD cells was measured by quantitative enzyme-linked immunosorbent assay (ELISA) using anti-mouse IgG F(ab)2'-specific antibody and HRP-conjugated anti-mouse IgG (Fc-specific) antibody. (c) The antigen-binding activity of the expressed antibody in the culture supernatants of the transfected RD cells was analyzed by indirect ELISA. (d) Human breast cancer cells (BT474) were incubated with increasing concentrations of human $\mathrm{Fc}(\mathrm{hFc})$ as a negative control, Herceptin as a positive control or the purified 4D5-mlgG2a for $72 \mathrm{~h}$ and evaluated by a water-soluble tetrazolium-1 assay. Data shown are the mean \pm s.d. from the triplicate experiments. OD, optical density. 
calculated as follows: length $\times$ width $^{2} \times 0.5$. At the end of the study, tumor tissues were taken out and weighed. The tumor growth inhibition rate was calculated using the formula inhibition rate $(\%)=(1-T / C) \times 100$, where $T$ and $C$ are the mean tumor volume or weight of the treated and control groups, respectively.

\section{Statistical analysis}

Data are presented as mean \pm s.d., and statistical comparisons between groups were performed using one-way analysis of variance followed by Dunnett's test. A value of $P<0.05$ was considered significant.

\section{RESULTS}

Construction of 4D5-mlgG antibody expression plasmids

To construct the expression plasmids for the anti-HER2 murine $\mathrm{mAb}$, the VL sequence of mumAb4D5 was modified by replacing asparagine at amino acid 65 with serine to remove a potential $\mathrm{N}$-glycosylation site (Asn65-Arg66-Ser67), similar to that of Herceptin. ${ }^{31}$ The modified VL of mumAb4D5 was fused to mouse $\mathrm{CK}_{K}$ to construct the light chain of mumAb4D5 while the $\mathrm{VH}$ of mumAb4D5 was fused to mouse $C_{\gamma} 1$ or $C \gamma 2 a$ to construct the $\gamma 1$ or $\gamma 2 a$ heavy chain of mumAb4D5, respectively. The genes encoding the heavy or light chain were codon- and RNAoptimized and fused to the Kozak and IgE leader sequences. These optimized heavy and light chain genes were synthesized and separately subcloned into the EcoRl-Notl sites of pVax1 to construct heavy (pVax1-4D5-mlgG1-H or pVax1-4D5mlgG2a-H) and light (pVax1-4D5-mlgG-L) chain expression plasmids, respectively (Figure 1). Thus the heavy and light chain genes were placed under the control of the strong human cytomegalovirus promoter for efficient expression in mammalian cells and tissues. The modified mumAb4D5 containing $\gamma 1$ or $\gamma 2 a$ was named $4 D 5-m l g G 1$ or $4 D 5-m l g G 2 a$, respectively.

In vitro expression of 4D5-mlgG in human muscle RD cells

The heavy and light chain expression plasmids for 4D5-mlgG1 or 4D5-mlgG2a were co-transfected into human muscle $\mathrm{RD}$ cells using lipofectamine, and the culture supernatants were analyzed by western blotting analysis and ELISA while pVax 1 was transfected into the cells as a negative control. The results showed that the 4D5-mlgG1 and 4D5-mlgG2a were expressed at similar levels (Figures $2 a$ and $b$ ) and exhibited the same HER2-binding activity (Figure $2 \mathrm{c}$ ). The antibody concentration in the culture supernatant was estimated to be $3.5 \mu_{\mathrm{g} \mathrm{ml}}^{-1}$ for $4 \mathrm{D} 5-\mathrm{mlgG} 1$ and $2.6 \mu \mathrm{g} \mathrm{ml}^{-1}$ for $4 \mathrm{D} 5-\mathrm{mlgG} 2 \mathrm{a}$, as assessed by quantitative ELISA.

In vivo expression analysis of 4D5-mlgG1 and 4D5-mlgG2a To evaluate in vivo expression of 4D5-mlgG, a mixture $(100 \mu \mathrm{g}$ per head) of the heavy and light chain expression plasmids or pVax1 (control) were intramuscularly injected into mice $(n=5$ per group), followed by EP. Then blood samples were taken at the indicated time points. The antibody concentrations of pooled sera were measured by an indirect ELISA using HER2-his as an antigen, and the isotype specificity of mlgG1 or mlgG2a was confirmed by an indirect ELISA using isotype-specific secondary antibodies (Figures $3 a-c$ ). The 4D5-mlgG1 and 4D5-mlgG2a antibodies were detectable by 7 days, peaked at 10-20 days and slowly declined, whereas no antibody was detected in the sera from the control mice receiving the pVax1 vector. Titers of 4D5-mlgG2a were higher than those of 4D5mlgG1, as assessed by indirect ELISA using purified antibody as a standard (Figure 3d). The peak serum concentration of 4D5mlgG2a was $152 \pm 33 \mu \mathrm{g} \mathrm{ml}^{-1}$.
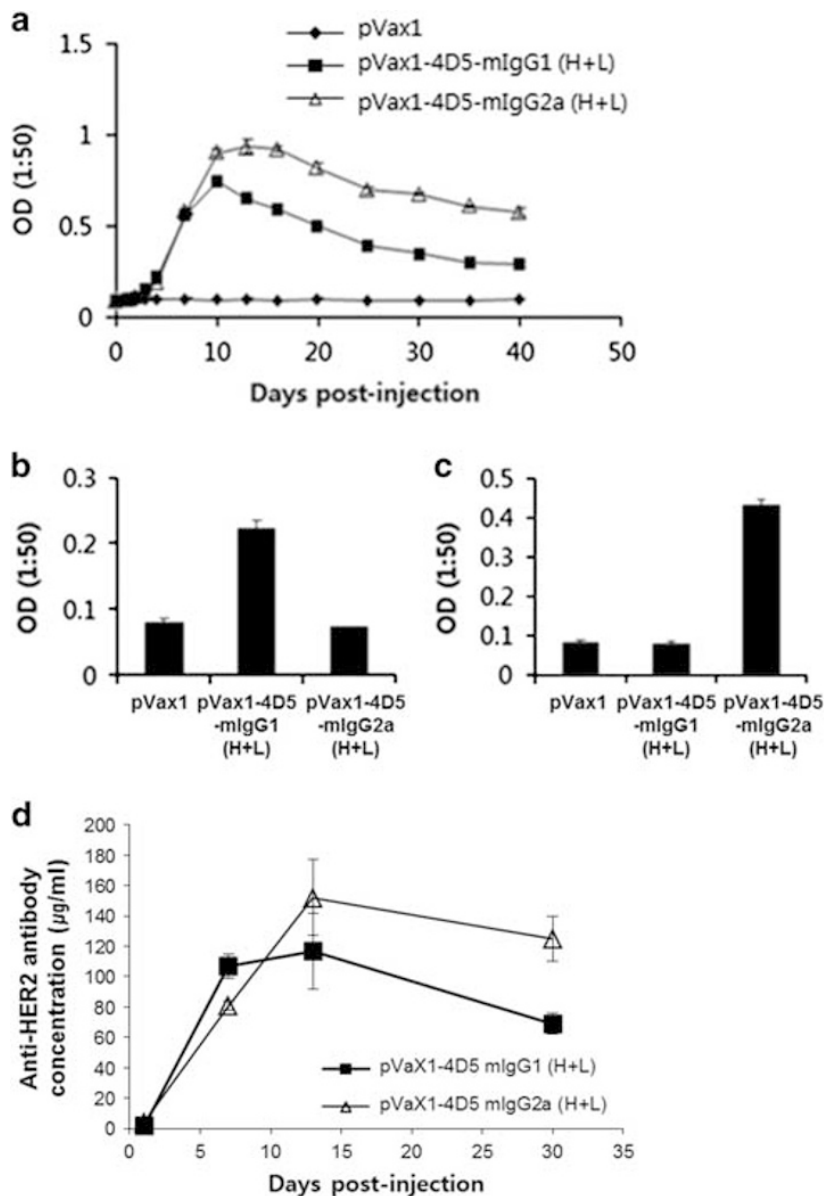

Figure 3. In vivo expression analysis of $4 \mathrm{D} 5-\mathrm{mlgG} 1$ and $\mathrm{mlgG} 2 \mathrm{a}$ in mice after intramuscular injection and electroporation. (a) A total of $100 \mu \mathrm{g}$ of the 4D5-mlgG1 or mlgG2a expression plasmids was injected into each BALB/c mouse ( $n=5 /$ group) and sera were taken at each time point. Sera were diluted 1:50 and then incubated in triplicate with HER2 antigen for indirect enzyme-linked immunosorbent assay (ELISA). Bound antibody was detected using goat anti-immunoglobulin $\mathrm{G}(\mathrm{lgG})(\mathrm{H}+\mathrm{L})$-horseradish peroxidase (HRP). (b and c) Indirect ELISA of the mouse sera using isotype-specific secondary antibody anti-lgG1-HRP (b) or anti-lgG2a-HRP (c). (d) The HER2-binding antibodies in the pooled sera were quantified by indirect ELISA using the purified 4D5-mlgG1 or mlgG2a antibody as standards. The values and bars represent the mean optical density (OD) and s.d.

Antitumor efficacy of anti-HER2 dMAb against a HER2-positive human breast tumor

We examined the antitumor activity of 4D5-mlgG2a because it was produced at a higher level than $4 \mathrm{D} 5-\mathrm{mlgG} 1$ in mouse sera. The expression plasmids were transfected into HEK293T cells and the antibody was purified from the culture supernatant by affinity chromatography using a Protein A column. The purified 4D5-mlgG2a antibody, Herceptin (positive control) or human Fc ( $\mathrm{hFc}$, negative control) was added to HER2-positive BT474 cells and evaluated by a WST-1 assay. The 4D5-mlgG2a inhibited the proliferation of the cells as effectively as Herceptin (Figure 2d).

To evaluate the in vivo antitumor efficacy of anti-HER2 dMAb, a BT474 xenograft nude mouse model was first established and the antitumor efficacy of Herceptin was tested. Herceptin $\left(8 \mathrm{mg} \mathrm{kg}^{-1}\right)$ or human Fc (2.7 $\mathrm{mg} \mathrm{kg}^{-1}$, control) was intravenously administered twice a week into the BT474 xenograft model for 28 days. 
a
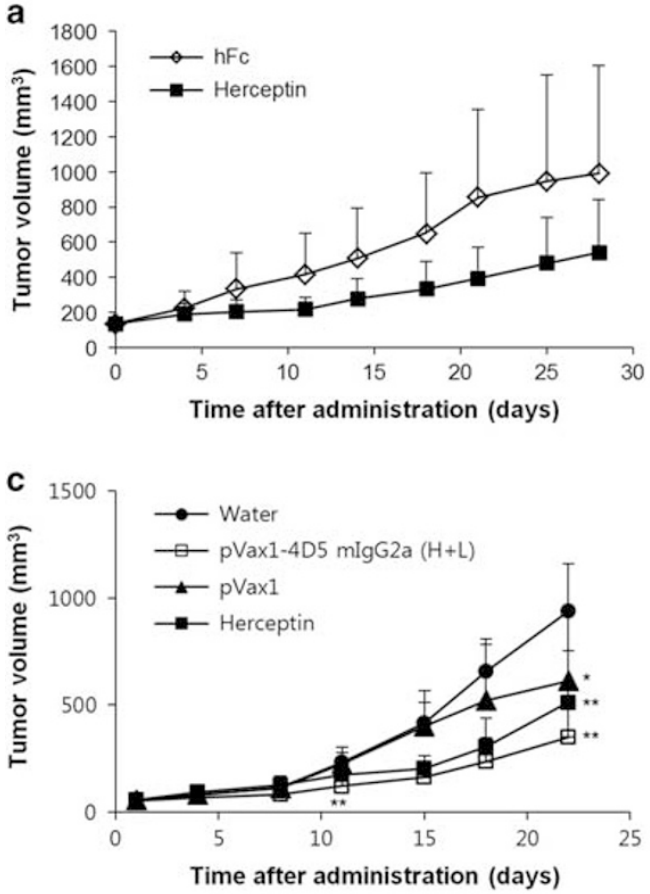

e

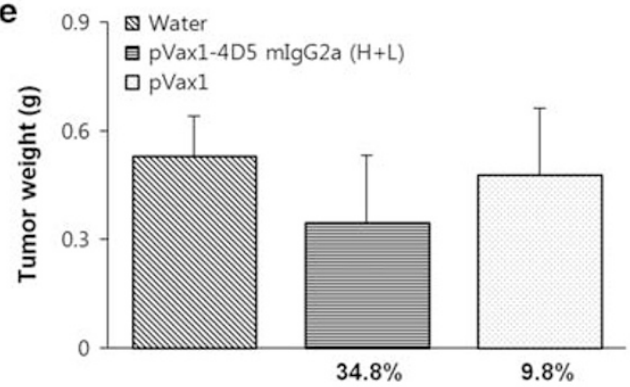

IR\% (tumor growth inhibition rate) b

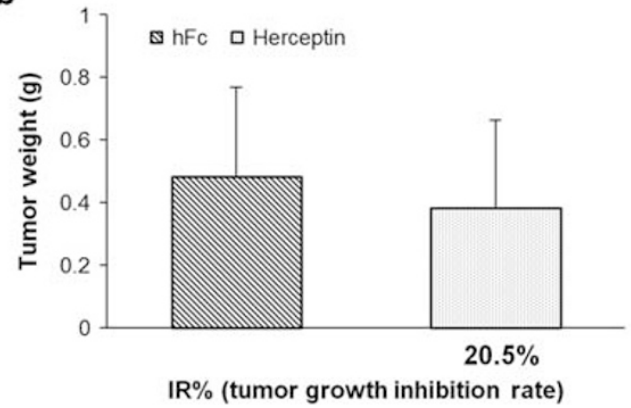

d

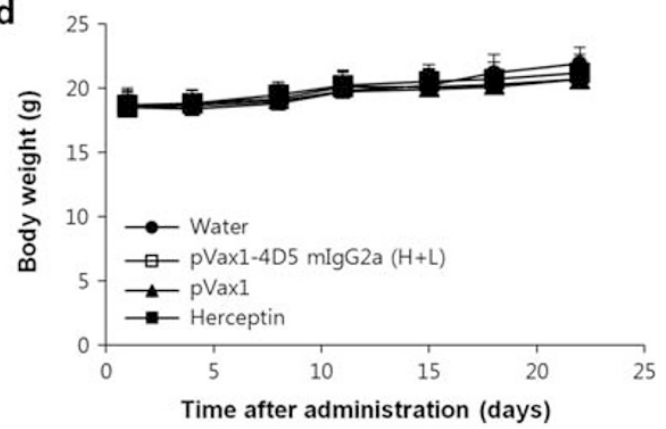

$\mathbf{f}$

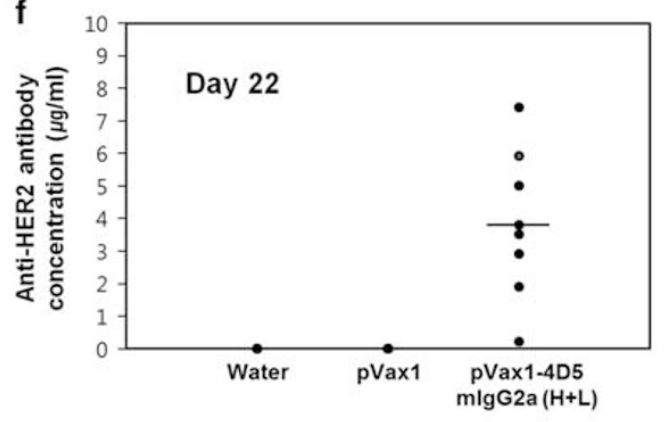

Figure 4. Antitumor activity mediated by pVax1-4D5-mlgG2a $(\mathrm{H}+\mathrm{L})$ in nude mice bearing BT474 xenografts. (a and b) Antitumor efficacy of Herceptin in a BT474 xenograft nude mouse model: Herceptin $\left(8 \mathrm{mg} \mathrm{kg}^{-1}\right)$ or hFc $\left(2.7 \mathrm{mg} \mathrm{kg}^{-1}\right)$ as a control was intravenously administered into each mouse twice a week for 4 weeks. Tumor volume was measured biweekly (a), and tumor weight was measured at the end of the experiment (b). Results are represented as the average \pm s.e. (c-e) Plasmid DNA or water was intramuscularly injected into nude mice ( $n=8$ per group) bearing BT474 xenografts. At day 7 after DNA injection, Herceptin (10 mg kg $\left.{ }^{-1}\right)$ was intravenously injected twice a week for 2 weeks. Tumor volume (c) and body weight (d) were measured twice a week while tumor weight (e) was measured at day 22. Results are represented as the average \pm s.e. (f) HER2-binding antibodies in the mouse sera were quantified by an indirect enzyme-linked immunosorbent assay using the purified 4D5-mlgG2a antibody as a standard. ${ }^{*} P<0.05$, significant difference from the negative control group by Dunnett's $t$-test. ${ }^{* *} P<0.01$, Significant differences from the negative control group by Dunnett's $t$-test. $\mathrm{IR}$, inhibition rate.

Herceptin moderately inhibited the tumor growth without affecting body weight (Figure 4a). Tumor volume was reduced by $54.6 \%$ in the Herceptin treatment group, compared with the isotype control. The tumor weight was decreased by $20.5 \%$ following the Herceptin treatment (Figure 4b).

Next the in vivo antitumor activity of anti-HER2 dMAb was evaluated in the same animal model. A single dose $(100 \mu \mathrm{g}$ per head) of the 4D5-mlgG2a expression plasmids, pVax1 or water was intramuscularly injected into nude mice $(n=8)$ bearing human breast carcinoma BT474 xenografts $\left(40-60 \mathrm{~mm}^{3}\right.$ in size), followed by EP. Seven days later, Herceptin $\left(10 \mathrm{mg} \mathrm{kg}^{-1}\right)$ was intravenously administered twice a week into the animal model for 14 days, because in the in vivo expression analysis, antibody was generated in the mouse sera by 7 days after the plasmid DNA injection. Tumor volumes were measured for 3 weeks and tumor weights were measured at day 22 after injection. Administration of 4D5-mlgG2a expression plasmids inhibited the tumor growth compared with the pVax1 vector without affecting body weight (Figures $4 \mathrm{c}$ and $\mathrm{d}$ ). Tumor volume was reduced by $43.0 \%$ in the 4D5-mlgG2a expression plasmid treatment group compared with the pVax1 treatment group while tumor weight was decreased by $27.6 \%$ (Figure $4 \mathrm{e}$ ). Herceptin inhibited the tumor growth by $45.4 \%$ compared with the water treatment group. The results indicate that the therapeutic efficacy of a single intramuscular injection of $100 \mu \mathrm{g}$ of the 4D5-mlgG2a expression plasmids is similar to that of four intravenous injections of $10 \mathrm{mg} \mathrm{kg}^{-1}$ Herceptin. Finally, the serum antibody concentration at the end of the experiment was measured by an indirect ELISA. The average antibody concentration of 4D5-mlgG2a was estimated to be $3.8 \mathrm{\mu g} \mathrm{ml}^{-1}$ (Figure 4f). The mouse having the highest serum antibody concentration had 
the smallest tumor volume, but the antibody concentration was not correlated with antitumor efficacy.

\section{DISCUSSION}

Intramuscular injection and in vivo EP of a dMAb, or plasmid DNA-encoded antibody, is effective in neutralizing viruses, such as the HIV and Dengue virus. ${ }^{29,30}$ However, dMAbs have not been evaluated for therapeutic purposes, such as tumor gene therapy. In this study, we constructed expression plasmids that expressed a parental murine antibody of Herceptin, as a model antibody, and evaluated the in vivo expression and antitumor efficacy. The antibody was functionally expressed in human RD cells and exhibited the same in vitro antitumor activity as Herceptin. A single intramuscular injection and in vivo EP of the plasmids $(100 \mu \mathrm{g}$ per head) resulted in high and sustained antibody expression in the sera of normal mice and in effective inhibition of tumor growth in nude mice bearing HER2-positive human breast carcinoma BT474 xenografts. The antitumor efficacy of the anti-HER2 dMAb $(100 \mu \mathrm{g})$ was similar to that of four doses of intravenously injected Herceptin $\left(10 \mathrm{mg} \mathrm{kg}^{-1}\right)$. The results suggest that the dMAb can be applied to tumor gene therapy. To our knowledge, our study is the first to show the effectiveness of the $\mathrm{dMAb}$ approach in tumor gene therapy.

Previous studies on tumor gene therapy showed that a single administration of adenovirus or adeno-associated virus carrying genes coding for an anti-HER2 mAb led to high expression levels of antibody in the serum with concomitant suppression of tumor growth in nude mice bearing HER2-positive carcinoma xenografts. ${ }^{14,32}$ However, there have been concerns that viral vectors can induce minor adverse effect such as fever, myalgia and disseminated infection as well as produce neutralizing antibody, thereby limiting multiple injections. ${ }^{33}$ Plasmid DNA is safe, stable, easily produced and well tolerated in humans. ${ }^{28,29}$ In addition, our study showed that the dMAb approach yields a high serum antibody concentration. Taken together, the dMAb strategy may have an advantage over viral vector-mediated gene delivery for tumor gene therapy.

Herceptin is administered either once a week or once every 3 weeks intravenously for 30-90 min to achieve a minimum serum level of $>10 \mu \mathrm{g} \mathrm{ml}^{-1}$. $^{34}$ The recommended duration of Herceptin treatment is currently 1 year or until the progression of the disease. In addition, as production of antibody requires high-cost manufacturing and complicated technologies, ${ }^{7-9}$ Herceptin therapy has been a burden on patients and the health-care system in terms of time and cost. In the present study, we observed that a single intramuscular injection of $100 \mu \mathrm{g}$ of the expression plasmids exhibited almost the same therapeutic efficacy as that of four intravenous injections of $10 \mathrm{mg} \mathrm{kg}^{-1}$ Herceptin. This result, taken together with the low production costs and simple manufacturing steps involved with plasmid DNA, suggests that dMAbs may be more simple and efficient than antibody protein therapy. Thus this approach may facilitate the application of therapeutic antibodies to a broader population and benefit more patients. In conclusion, we have demonstrated the therapeutic effectiveness of anti-HER2 dMAb in the treatment of HER2-positive breast cancer and found that dMAb is an attractive tumor therapy approach.

\section{CONFLICT OF INTEREST}

The authors declare no conflict of interest.

\section{ACKNOWLEDGEMENTS}

The study was supported by a 2014 research grant from GeneOne Life Science, Inc. It was also supported in part by a grant from the National R\&D program for Cancer Control, Ministry of Health and Welfare, Republic of Korea (1020420) and 2016 Research Grant from Kangwon National University.

\section{REFERENCES}

1 Ecker DM, Jones SD, Levine HL. The therapeutic monoclonal antibody market. MAbs 2015; 7: 9-14.

2 Beck A, Wurch T, Bailly C, Corvaia N. Strategies and challenges for the next generation of therapeutic antibodies. Nat Rev Immunol 2010; 10: 345-352.

3 Goldenberg MM. Trastuzumab, a recombinant DNA-derived humanized monoclonal antibody, a novel agent for the treatment of metastatic breast cancer. Clin Ther 1999; 21: 309-318.

4 Herbst RS, Kim ES, Harari PM. IMC-C225, an anti-epidermal growth factor receptor monoclonal antibody, for treatment of head and neck cancer. Expert Opin Biol Ther 2001; 1: 719-732.

5 Jonker DJ, O'Callaghan CJ, Karapetis CS, Zalcberg JR, Tu D, Au HJ et al. Cetuximab for the treatment of colorectal cancer. N Engl J Med 2007; 357: 2040-2048.

6 Maloney DG, Grillo-López AJ, White CA, Bodkin D, Schilder RJ, Neidhart JA et al. IDEC-C2B8 (Rituximab) anti-CD20 monoclonal antibody therapy in patients with relapsed low-grade non-Hodgkin's lymphoma. Blood 1997; 90: 2188-2195.

7 Barnes LM, Bentley CM, Dickson AJ. Stability of protein production from recombinant mammalian cells. Biotechnol Bioeng 2003; 81: 631-639.

8 Reiter M, Blüml G. Large-scale mammalian cell culture. Curr Opin Biotechnol 1994; 5: 175-179.

9 Trill JJ, Shatzman AR, Ganguly S. Production of monoclonal antibodies in COS and CHO cells. Curr Opin Biotechnol 1995; 6: 553-560.

10 Cotrim AP, Baum BJ. Gene therapy: some history, applications, problems, and prospects. Toxicol Pathol 2008; 36: 97-103.

11 Friedmann T. The Development of Human Gene Therapy. Cold Spring Harbor Laboratory Press: New York, USA, 1999.

12 Kay MA, Glorioso JC, Naldini L. Viral vectors for gene therapy: the art of turning infectious agents into vehicles of therapeutics. Nat Med 2001; 7: 33-40.

13 Zhang C, Wang QT, Liu H, Zhang ZZ, Huang WL. Advancement and prospects of tumor gene therapy. Chin J Cancer 2011; 30: 182-188.

14 Jiang $M$, Shi W, Zhang Q, Wang X, Guo M, Cui Z et al. Gene therapy using adenovirus-mediated full-length anti-HER-2 antibody for HER-2 overexpression cancers. Clin Cancer Res 2006; 12(Pt 1): 6179-6185.

15 Shedlock DJ, Silvestri G, Weiner DB. Monkeying around with HIV vaccines: using rhesus macaques to define 'gatekeepers' for clinical trials. Nat Rev Immunol 2009; 9: 717-728.

16 Kutzler MA, Weiner DB. DNA vaccines: ready for prime time? Nat Rev Genet 2008; 9: 776-788.

17 Mallilankaraman K, Shedlock DJ, Bao H, Kawalekar OU, Fagone P, Ramanathan AA et al. A DNA vaccine against chikungunya virus is protective in mice and induces neutralizing antibodies in mice and nonhuman primates. PLoS Negl Trop Dis 2011; 5: e928.

18 Yan J, Yoon H, Kumar S, Ramanathan MP, Corbitt N, Kutzler M et al. Enhanced cellular immune responses elicited by an engineered HIV-1 subtype $B$ consensusbased envelope DNA vaccine. Mol Ther 2007; 15: 411-421.

19 Morrow MP, Yan J, Pankhong P, Shedlock DJ, Lewis MG, Talbott K et al. IL-28B/IFNlambda 3 drives granzyme B loading and significantly increases CTL killing activity in macaques. Mol Ther 2010; 18: 1714-1723.

20 Lang Kuhs KA, Ginsberg AA, Yan J, Wiseman RW, Khan AS, Sardesai NY et al. Hepatitis $C$ virus NS3/NS4A DNA vaccine induces multiepitope T cell responses in rhesus macaques mimicking human immune responses [corrected]. Mol Ther 2012; 20: 669-678.

21 Bagarazzi ML, Yan J, Morrow MP, Shen X, Parker RL, Lee JC et al. Immunotherapy against HPV16/18 generates potent $\mathrm{TH} 1$ and cytotoxic cellular immune responses. Sci Transl Med 2012; 4: 155ra138.

22 Hirao LA, Draghia-Akli R, Prigge JT, Yang M, Satishchandran A, Wu L et al. Multivalent smallpox DNA vaccine delivered by intradermal electroporation drives protective immunity in nonhuman primates against lethal monkeypox challenge. J Infect Dis 2011; 203: 95-102.

23 Laddy DJ, Yan J, Khan AS, Andersen H, Cohn A, Greenhouse J et al. Electroporation of synthetic DNA antigens offers protection in nonhuman primates challenged with highly pathogenic avian influenza virus. J Virol 2009; 83: 4624-4630.

24 Weiner DB. DNA vaccines: crossing a line in the sand. Introduction to special issue. Vaccine 2008; 26: 5073-5074.

25 Donnelly JJ, Ulmer JB, Shiver JW, Liu MA. DNA vaccines. Annu Rev Immunol 1997; 15: 617-648.

26 Sugar IP, Neumann E. Stochastic model for electric field-induced membrane pores. Electroporation. Biophys Chem 1984; 19: 211-225.

27 Sugar IP, Förster W, Neumann E. Model of cell electrofusion. Membrane electroporation, pore coalescence and percolation. Biophys Chem 1987; 26: 321-335.

28 Wolf $\mathrm{H}$, Rols MP, Boldt E, Neumann E, Teissié J. Control by pulse parameters of electric field-mediated gene transfer in mammalian cells. Biophys $J 1994 ; 66$ (Pt 1): 524-531.

29 Muthumani K, Flingai S, Wise M, Tingey C, Ugen KE, Weiner DB. Optimized and enhanced DNA plasmid vector based in vivo construction of a neutralizing 
anti-HIV-1 envelope glycoprotein Fab. Hum Vaccin Immunother 2013; 9: 2253-2262.

30 Flingai S, Plummer EM, Patel A, Shresta S, Mendoza JM, Broderick KE et al. Protection against dengue disease by synthetic nucleic acid antibody prophylaxis/immunotherapy. Sci Rep 2015; 5: 12616.

31 Carter P, Presta L, Gorman CM, Ridgway JB, Henner D, Wong WL et al. Humanization of an anti-p185HER2 antibody for human cancer therapy. Proc Natl Acad Sci USA 1992; 89: 4285-4289.

32 Wang G, Qiu J, Wang R, Krause A, Boyer JL, Hackett NR et al. Persistent expression of biologically active anti-HER2 antibody by AAVrh.10-mediated gene transfer. Cancer Gene Ther 2010; 17: 559-570.

33 Razi Soofiyani S, Baradaran B, Lotfipour F, Kazemi T, Mohammadnejad L. Gene therapy, early promises, subsequent problems, and recent breakthroughs. Adv Pharm Bull 2013; 3: 249-255.
34 Leyland-Jones B, Arnold A, Gelmon K, Verma S, Ayoub JP, Seidman A et al. Pharmacologic insights into the future of trastuzumab. Ann Oncol 2001; 12(Suppl 1): S43-S47.

(i) $\Theta$ This work is licensed under a Creative Commons Attributioncc. NonCommercial-NoDerivs 4.0 International License. The images or other third party material in this article are included in the article's Creative Commons license, unless indicated otherwise in the credit line; if the material is not included under the Creative Commons license, users will need to obtain permission from the license holder to reproduce the material. To view a copy of this license, visit http:// creativecommons.org/licenses/by-nc-nd/4.0/

(c) The Author(s) 2016 